\title{
Distribuição espacial da precipitação para o Estado Mato Grosso do Sul
}

\author{
Amaury de Souza ${ }^{\mathrm{I}}$; Hamilton Germano Pavão ${ }^{\mathrm{I}}$; Giancarlo Lastoria ${ }^{\mathrm{II}}$; Sandra Garcia Gabas ${ }^{\mathrm{II}}$; \\ Antonio Conceição Paranhos Filho ${ }^{\text {II }}$, Guilherme Henrique Cavazzana ${ }^{\text {III }}$. \\ I Depto de Física, Centro de Ciências Exatas e Tecnologia, Universidade Federal de Mato \\ Grosso do Sul, caixa postal 549, CEP 79070-900, Campo Grande-MS, Brasil, \\ amaury@nin.ufms.br; pavão@nin.ufms.br; \\ ${ }^{\mathrm{II}}$ Depto de Hidráulica e Transportes, Centro de Ciências Exatas e Tecnologia, Universidade \\ Federal de Mato Grosso do Sul, caixa postal 549, CEP 79070-900, Campo Grande-MS Brasil, \\ lastoria@nin.ufms.br; sandragabas@nin.ufms.br; paranhos@nin.ufms.br; \\ III Mestrando do Programa de Pós Graduação em Tecnologias Ambientais, Centro de Ciências \\ Exatas e Tecnologia, Universidade Federal de Mato Grosso do Sul, Brasil. \\ cavazzana.ea@gmail.com
}

\begin{abstract}
Abstrat: The objective of this study was to evaluate the probable monthly precipitation spatial behavior in the Mato Grosso do Sul State, considering a 75\% probability and using 08 meteorological stations that had registered information series for over 20 years. Classical statistics was used to adjust the theoretical probability pattern, which was called gamma probability distribution model. Through geostatistics, precipitation scores calculated by the gamma probability distribution model were georeferenced and experimental semivariogram patterns were developed using georeference techniques. This allowed data interpolation and map generation for the studied period, showing concisely precipitation variability. Probable monthly precipitation spatial distribution varied according to supposed weat her levels; and spatial precipitation behavior was similar in all series, except for the June one, which presented a standard difference in relation to the other series. Lower scores of probable precipitation occurred in the northwestern-northern area of the studied mesoregion.
\end{abstract}

Palavra-chave: Pluvial Monthly Precipitation; Spatial Variability. 


\section{Introdução}

A água é um bem insubstituível à manutenção da vida e a sua circulação na Terra ocorre sob um processo natural conhecido como ciclo hidrológico.

A precipitação é a fase deste ciclo responsável pelo transporte das águas da atmosfera à superfície terrestre. $\mathrm{O}$ conhecimento quantitativo da sua variabilidade espacial sobre as regiões, ou bacias hidrográficas, deve ser entendido como imprescindível ao eficiente planejamento e gerenciamento dos recursos hídricos.

No caso da escassez prolongada, geralmente imposta pelas longas estiagens, os órgãos gestores têm recorrido às ações prioritárias que visam à mitigação do cenário, utilizando medidas alternativas de suprimentos, algumas vezes em avançados estágios de calamidades, principalmente nos locais onde o clima é seco. Por outro lado, os excessos dos volumes precipitados historicamente, revelaram situações de sinistros, com constatações de graves prejuízos à vida e ao patrimônio público e privado.

Por se tratar de um fenômeno natural aleatório, a distribuição espacial da precipitação não se repete exatamente a cada período anual sob o aspecto quantitativo, embora aponte, com certo grau de certeza, os locais onde se deve esperar que chova mais ou menos. Por outro lado, os locais onde ocorrem as disponibilidades hídricas nem sempre são os que no momento demandam maiores consumos emergenciais.

Para isto, a Engenharia Hidrológica desenvolve modelos que visam aperfeiçoar as tomadas de decisão para o controle mais eficaz do manejo hídrico.

Sendo assim, este conhecimento passa então a constituir uma ferramenta importante, desde que utilizadas séries pluviométricas com qualidade e densidade que atendam aos limites satisfatórios, métodos de interpolação de precisão comprovada, e, finalmente, uso de programas computacionais avançados.

O conhecimento da variabilidade espacial da precipitação é determinante para o processo de planejamento de atividades primordiais da vida do homem, como: os projetos agrícolas, projetos de proteção e conservação de solos, planejamento de atividades turísticas e de lazer, construção de barragens e reservatórios, previsão de enchentes, obras de regularização de vazões e controle de estiagens, além de uma infinidade de atividades nas quais a precipitação tem uma interferência menos direta, mas não menos importante.

O planejamento das ações que determinam algumas decisões em vários setores da economia requer uma análise temporal e espacial da precipitação sempre associada a uma probabilidade, visto que o comportamento da precipitação tem caráter eminentemente aleatório e de grande complexidade e diversidade. De acordo com LANNA (1997), para quantificar uma variável hidrológica deve ser percebido que os processos hidrológicos desenvolvem-se no tempo e no espaço.

Por exemplo, a chuva tem uma variação temporal e, por isso, uma variável que a quantifique deve assumir valores distintos ao longo do tempo. Ela também varia ao longo do espaço, ou seja, a variável representativa deveria assumir valores distintos em função das coordenadas do ponto geográfico de interesse. GUERRA (1988) concorda que estas variáveis têm em comum uma dupla característica: são aleatórias já que os valores numéricos observados podem variar consideravelmente de um ponto a outro no espaço; são espaciais e porque apesar de muito variáveis dentro do espaço, os valores numéricos observados não são inteiramente independentes.

Nos fenômenos espaciais estruturados, como a pluviometria de uma região, destacamse duas características comuns que, aparentemente sem ligação são, no entanto, a razão da aplicação dos modelos probabilísticos e, em particular, dos modelos das funções aleatórias: em primeiro lugar, são entidades que se distribuem no espaço de um modo não aleatório, isto é, com certa estrutura; em segundo lugar, as amostras e observações disponíveis sobre aqueles 
fenômenos espaciais são, na sua maioria, parceladas, discretas e normalmente escassas, o que faz com que ao seu conhecimento global esteja sempre associada uma determinada incerteza (SOARES, 2000).

O problema básico a resolver com a geoestatística é o da caracterização da distribuição espacial das grandezas (quantidade e qualidade de recursos naturais) e o da avaliação de medidas de incerteza, tendo em conta a maior ou menor variabilidade do fenômeno espacial, a qualidade das amostras e observações, o tipo de modelo geoestatístico escolhido e o maior ou menor grau de conhecimento que se tem do fenômeno (SOARES, 2000).

$\mathrm{Na}$ teoria fundamental da geoestatística tem-se sempre a esperança de que, na média, as amostras mais próximas no tempo e no espaço sejam, de certo, mais similares entre si do que as que estiverem mais distantes (ISAAKS; SRIVASTAVA, 1989).

O semivariograma é uma ferramenta básica de suporte às técnicas de krigagem, que permite representar quantitativamente a variação de um fenômeno regionalizado no espaço. $\mathrm{O}$ semivariograma é fundamental na decisão para aplicação da geoestatística, porque determina, sobretudo, a dependência espacial entre as amostras, a Krigagem é um procedimento de interpolação de valores em uma superfície contínua. Difere dos outros métodos de interpolação por fazer uso explicitamente da variância entre os valores observados, o variograma. Baseia-se na combinação linear ponderada dos dados disponíveis, aplicada ao modelo de variograma adotado.

O objetivo básico do método geoestatístico, por meio da krigagem, é interpolar valores de pontos ou áreas que não são amostradas, usando dados de pontos amostrados adjacentes (PHILLIPS, 1992).

Neste contexto, o presente estudo tem como objetivo fundamental a análise, discussão e avaliação do comportamento da variabilidade espacial da precipitação mensal provável do estado do Mato Grosso do Sul, considerando o nível de $75 \%$ de probabilidade, bem como, a análise do ajuste das séries amostrais de precipitação mensal ao modelo teórico de distribuição gama de probabilidade.

\section{Materiais e Métodos}

Os dados diários, mensais e anuais pluviométricos do período compreendido entre os anos de 1979 e 2008, foram fornecidos pelo INEMET, que permitiram analisar o comportamento das chuvas no decorrer do tempo. A partir dos dados diários e mensais de precipitação, foi possível a identificação e análise de variáveis, bem como sua distribuição sazonal e espacial e períodos secos.

Para a identificação dos períodos secos, utilizou-se como metodologia a contagem de períodos superiores a 75 dias sem a ocorrência de precipitações e/ou sem a ocorrência de chuvas significativas (precipitações acima de $2,5 \mathrm{~mm}$, valor inferior à evapotranspiração potencial diária do período).

A partir dos registros, por meio de rotinas de programação procedeu-se à leitura dos dados, a detecção de dados faltantes e o tamanho das séries, selecionando, desta maneira, as estações pluviométricas a serem utilizadas neste estudo.

O tamanho das séries históricas selecionadas foi determinado, em função da real existência dos dados e de forma a conter, minimamente, elementos meteorológicos com período superior a 20 anos de registros, uma vez que o nível de informações disponíveis, relativo ao escopo e a área determinada para este estudo, são ainda muito escassos.

Melhor estudo seria possível, notadamente, com séries de dados extensas, no entanto, por ser uma região de colonização muito recente, os dados e informações são também precipuamente recentes. 
No entanto, conforme salienta BAILEY (1990), para um bom estudo da necessidade de irrigação de uma dada região devem ser analisados os elementos meteorológicos de um período de aproximadamente vinte anos.

Os dados faltantes, nas referidas séries, foram preenchidos por meio de uma rotina de programação computacional, utilizando-se, para isso, o Método de Ponderação Regional.

Para a área experimental adotada, do Estado do Mato Grosso do Sul, foram selecionadas as séries mensais históricas de 08 estações pluviométricas.

Considerou-se, entre as 08 estações, 10 estações de entorno da área experimental com o propósito de melhorar a cobertura no processo de interpolação e consequientemente gerar mapas mais homogêneos e precisos dentro da área de estudo.

Foram utilizadas, no presente estudo, as ferramentas da estatística clássica e da geoestatística. A estatística clássica foi aplicada quando, a partir das séries mensais, procedeuse a um ajuste para o modelo probabilístico teórico denominado modelo gama de distribuição de probabilidades.

Para a devida validação do ajuste foram utilizados os testes de aderência de Kolmogorov-Smirnov e Qui-quadrado, com significância de 5\% de probabilidade

\section{Resultados e Discussões}

Os mapas de contorno, para os valores da precipitação provável associada ao nível de $75 \%$ de probabilidade, para cada mês, foram construídos considerando-se como base os parâmetros de ajuste e os modelos ajustados dos semivariogramas, para análise do comportamento espacial das séries em estudo.

Os mapas relativos às séries correspondentes aos meses de abril, maio, junho, julho e dezembro, respectivamente representados pela Figura 01 considerando-se a condição de independência espacial dos referidos dados, foram construídos a partir do processo de interpolação pelo método do inverso do quadrado da distância, enquanto que os mapas para as séries correspondentes aos meses de janeiro, fevereiro, março, agosto, setembro, outubro e novembro, respectivamente representados pelas figuras foram construídos a partir do processo de interpolação pelo método da krigagem.

Na Figura 01, está configurado o comportamento espacial da precipitação mensal provável da série, janeiro, que apresentou variabilidade da precipitação com redução da intensidade no sentido norte-sul.

Observou-se também uma intensidade de precipitação maior sobre a região norte do mapa, com predominância, nesta mesma região, para o sentido oeste-leste. A série do mês de fevereiro, visualizada na Figura 01, apresentou comportamento espacial semelhante à precipitação relativa à série de janeiro, inclusive guardando semelhança nos respectivos valores, porém, caracterizando ainda mais a variabilidade no sentido leste-oeste, já o mês de que representa março, no qual o comportamento espacial da precipitação ocorreu de forma pouco diferenciada relativamente aos meses de janeiro e fevereiro, com a concentração dos valores maiores na região nordeste e predominância de redução de intensidade para o sentido sudeste - noroeste, a partir do centro-sul. 

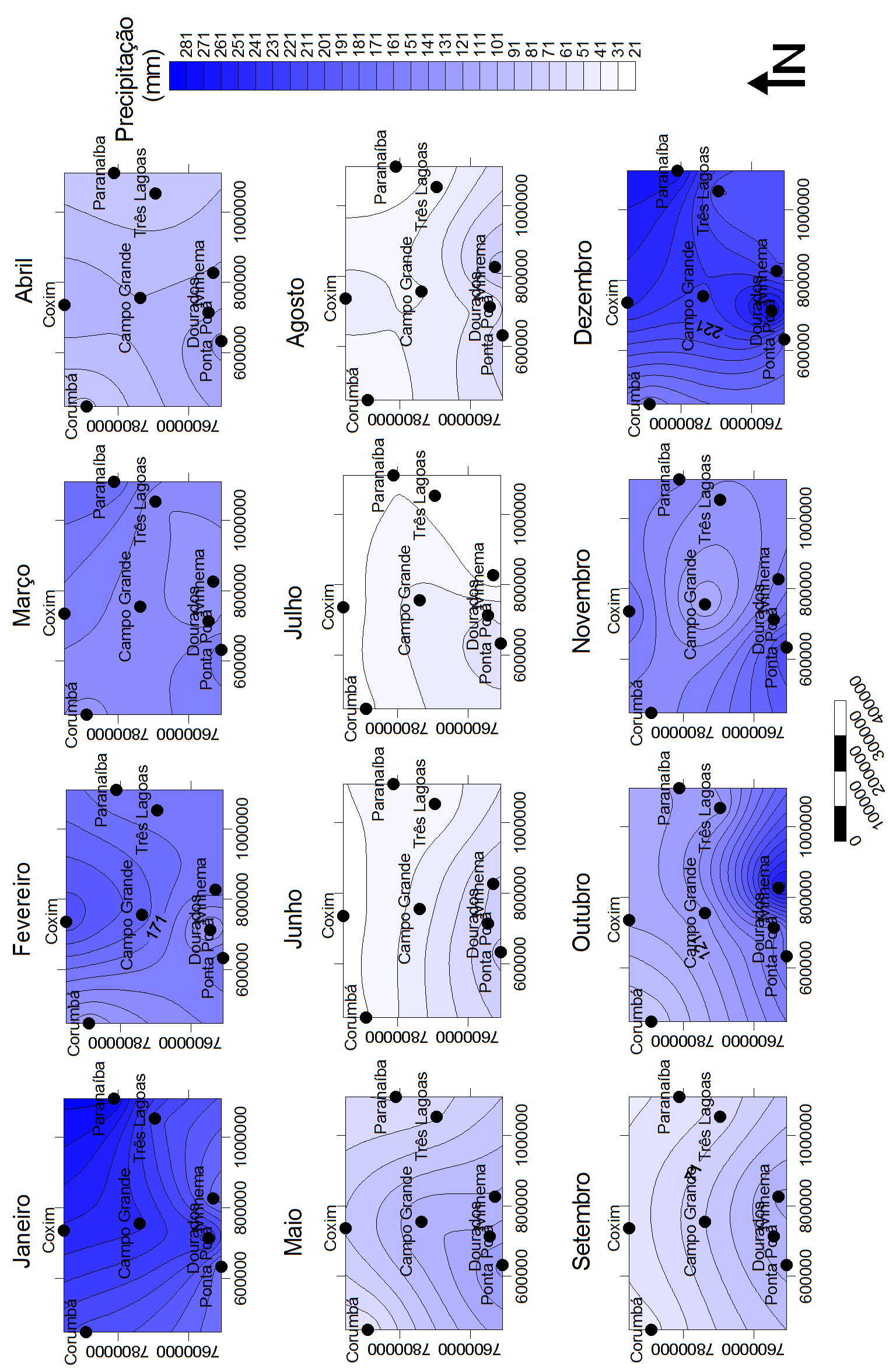

Figura 01: Distribuição espacial mensal da precipitação em Mato Grosso do Sul. 
Nota-se também certa homogeneidade nos valores no sentido centro-leste do referido mapa, ocorrendo assim à maior variabilidade na direção norte-sul com aumento da intensidade a partir do centro-sul, no sentido norte.

A série relativa ao mês de abril, apresentada na Figura 01, coincide com o início do outono e se caracteriza por relativo decréscimo na intensidade da precipitação provável. Essa série apresentou comportamento espacial similar a dos meses anteriores, todavia, com o surgimento de intensidades pontuais isoladas e diferenciadas ao longo de toda a região.

Para a série relativa ao mês de maio, de acordo com a Figura 01, o comportamento espacial da precipitação provável apresentou-se de forma bastante variável, com os maiores valores ocorrendo na região sudoeste e diminuindo radialmente para os extremos, exceto para o sentido sudeste, a partir do centro, visto que, neste sentido, os valores de precipitação guardaram certa homogeneidade, apresentando assim, uma variação menor. Também nesta série ocorreu o surgimento de intensidades pontuais isoladas e diferenciadas ao longo da região.

Para o mês de junho, que representa o final do outono e o início do inverno, conforme Figura 01, o comportamento espacial da precipitação provável apresentou tendência de concentração dos valores maiores na região sul do mapa, ao passo que os menores valores concentraram-se na região sul-sudeste e extremo leste do mesmo.

Na série relativa ao mês de julho, apresentada na Figura 01, o comportamento espacial da precipitação provável apresentou tendência de concentração dos menores valores na região norte - noroeste e sudoeste do mapa. A maior variabilidade observada ocorreu na direção norte-sul. Os menores valores da precipitação provável apresentaram-se no mês de agosto, visualizados na Figura 01, e ocorreram no norte da região. O comportamento espacial neste mês variou no sentido norte-sul, aumentando $100 \%$ de um extremo ao outro

$\mathrm{O}$ mapa relativo à série do mês de setembro, já no final do inverno, demonstra uma variabilidade no comportamento da precipitação provável no sentido noroeste-sudeste, bem caracterizado, com crescimento da intensidade neste sentido.

Na série relativa ao mês de outubro, mostrada na Figura 01, o comportamento espacial da precipitação provável apresentou-se com a concentração dos menores valores nas regiões extremas do mapa, exceto para a região sul, e por meio de isolinhas concêntricas os valores diminuíram até o centro da região.

O comportamento espacial da precipitação provável para a série relativa ao mês de novembro, observado, demonstrou uma variabilidade com a apresentação dos maiores valores no centro-sul da região crescendo radialmente no sentido norte e sudeste mais intensamente, a partir do centro e, do mesmo modo, no sentido leste e oeste, porém, de forma menos intensa. Observou-se ainda que no sentido sudeste, a partir do centro, ocorreu relativa homogeneidade no comportamento dos valores de precipitação.

O mês de dezembro, apresentado na figura, representa o início do verão e o término da primavera, em que o comportamento espacial da precipitação provável, para este mês, apresentou-se de forma mais homogênea, visto que a diferença entre o maior e o menor valor não ultrapassou a $18 \%$. A sua intensidade ocorreu de forma pontual e mais intensa no centronorte da região e a maior variabilidade ocorreu no sentido leste-oeste.

A dispersão de intensidades pontuais isoladas ao longo da região ocorreu de forma idêntica às séries relativas aos meses de abril, maio, junho e julho, em razão da independência espacial entre os dados.

Por meio da análise elaborada para cada série, concluiu-se que as séries relativas aos meses de janeiro, fevereiro e março - que correspondem à estação de verão - guardam entre si uma relação de similaridade no comportamento espacial da precipitação provável, com 
variação extremamente bem definida no sentido noroeste-sudeste, com os menores valores ocorrendo no setor noroeste e os maiores valores no setor sudeste da região.

As séries mensais de abril, maio e junho - que correspondem à estação de outono apresentaram um comportamento espacial diferenciado sob o aspecto geográfico na apresentação das isolinhas da precipitação provável no âmbito da região e, notadamente, um comportamento similar com relação à intensidade da referida precipitação.

Com referência aos meses de julho, agosto e setembro, meses correspondentes à estação de inverno, o comportamento espacial caracterizou-se pela diferença considerável entre as séries, do ponto de vista das isolinhas, sobretudo, para os meses de julho e agosto. Essa estação caracterizou-se pela ocorrência dos menores valores de precipitação provável do ano.

As séries relativas a outubro, novembro e dezembro, meses correspondentes à estação de primavera, comportaram-se espacialmente de maneira similar com relação à apresentação geográfica dos maiores valores da precipitação provável no mapa, no entanto, com uma grande diferenciação para os menores valores.

A série relativa ao mês de dezembro caracterizou-se diferencialmente das séries de outubro e novembro pela ocorrência de intensidades pontuais isoladas. Contudo, pode-se salientar que o comportamento espacial da precipitação mensal para a mesorregião em estudo, como de outras regiões, pode ser avaliado pelos mapas de contorno, cujas informações, contidas nos mapas, são muito úteis para melhor entender a variabilidade das propriedades da precipitação pluvial.

O comportamento espacial das séries mensais de precipitação possui uma estreita correlação com a variação temporal considerando os padrões de comportamento encontrados, pôde-se avaliar que os locais com menores índices do percentil 75 da precipitação mensais são variáveis de acordo com os níveis temporais - e a variação altimétrica e a correlação linear entre altitude e precipitação é altamente significativa, indicando que é plausível usar altitude com variável colocalizada na distribuição espacial de precipitação.

A distribuição da precipitação nas quatro estações do ano, considerando-se a média do percentil 75 da precipitação mensal provável, determinou, para a região em estudo, para o período de verão $28,21 \%$ de disponibilidade hídrica pluvial, para o período de outono $21,16 \%$, para o período de inverno $15,45 \%$ e para o período de primavera $35,18 \%$, caracterizando, desta forma, uma estação seca que corresponde aos meses de abril a setembro $(36,6 \%)$ e uma estação chuvosa que corresponde aos meses de outubro a março $(63,4 \%)$, com ocorrência de maior precipitação para os meses de Outubro, Novembro e Dezembro.

Também RIBEIRO \& LUNARDI (1997), através da Função Gama, observaram que $66 \%$ do total de chuva do ano concentrávamos-se nos meses de outubro a março e que dezembro caracterizava-se como o mês mais chuvoso representando $14,5 \%$ da chuva anual e agosto o mês menos chuvoso com apenas 3,3\% de precipitação. BRATH, MONTANARI \& TOTH (2004) em seu estudo afirmam que os maiores eventos de precipitação ocorrem de outubro a abril.

Este estudo tratou da variabilidade mensal e considerou os totais mensais de precipitação de séries históricas de pelo menos 20 anos. É fato que todos os fenômenos que influenciam a variabilidade da precipitação em períodos maiores que o período mensal influencia também a variabilidade desse período.

A altura média da precipitação durante o ano sobre o Mato Grosso do Sul apresenta uma distribuição de um núcleo mais chuvoso ao norte, Coxim com $1.492 \mathrm{~mm}$ com decréscimo para E e W. No extremo W, o regime cai a $1.117 \mathrm{~mm}$, Corumbá, no Pantanal SulMato-Grossense, e na região sul onde apresenta os maiores valores de $1660 \mathrm{~mm}$, Ponta Porã. 
Em contrapartida, o inverno é excessivamente seco. Nessa época do ano as chuvas são muito raras, havendo, em média, geralmente, 4 a 5 dias de ocorrência deste fenômeno por mês, sendo mais raras no setor oeste de Mato Grosso do Sul, onde, pelo menos um mês, não registra sequer 1 dia de chuva. A seca acontece no trimestre de inverno, ou seja, junho-julhoagosto.

É possível observar a média pluviométrica regional é de $1.446 \mathrm{~mm}$, com uma variação na precipitação média anual entre $1.117 \mathrm{~mm}$ (Corumbá) e $1.660 \mathrm{~mm}$ (Ivinhema). No que diz respeito à variação sazonal dos índices de precipitação, observa-se que no decorrer do ano as chuvas seguem a regra geral observada na região dos cerrados, apresentando duas estações bem definidas: um verão quente e chuvoso e um inverno seco, com temperaturas mais amenas.

Durante a estação seca é possível observar longos períodos sem ocorrência de chuvas e/ou com chuvas insignificantes, bem abaixo da evapotranspiração (Etp) diária e que não altera a condição de secura do ambiente. Esses períodos, não raro chegam a superar os 100 dias.

Durante o período de análise, a quantidade de anos e a média de dias seguidos que ocorreram tais períodos secos prolongados, tendo como referência aqueles superiores aos 75 dias consecutivos.

Também se observa que as médias de dias, nos anos em que ocorreram longos períodos secos acima do limite mínimo da pesquisa foram de 105 dias, e a média de dias sem chuvas significativas (menor que $2,5 \mathrm{~mm}$ ) é de 110 dias e que praticamente metade dos anos apresenta um longo período sem chuvas superando os 75 dias ininterruptos. Tal período coincide com a época do ano da estação seca, sendo mais comum sua ocorrência nos meses de junho, julho e agosto podendo chegar até em meados de setembro

\section{Conclusão}

Com relação ao ajuste para um modelo probabilístico teórico foi possível constatar que as séries de precipitações mensais da mesorregião, para cada uma das estações, podem ser adequadamente representadas pela função de distribuição gama de probabilidade.

Com relação à variabilidade espacial da precipitação provável associada ao nível de $75 \%$ de probabilidade, para a região estudada, concluiu-se que: A distribuição espacial da precipitação provável sofreu variações de acordo com os níveis temporais pressupostos e o comportamento, tendo em vista os mapas de contorno das séries mensais, demonstrou semelhança entre as mesmas, com exceção para a série de junho, que apresentou diferença de padrão relativamente às demais séries.

A série relativa ao mês de junho apresentou variabilidade na intensidade da precipitação provável no sentido noroeste-sudeste, com concentração dos maiores valores no setor noroeste do mapa, enquanto as demais séries apresentaram-se com concentração dos maiores valores no setor sudeste do mapa.

Os menores valores da precipitação provável ocorreram no setor noroeste-norte da mesorregião em estudo. As séries mensais da precipitação provável, da região em estudo, apresentaram, para as séries relativas aos meses de fevereiro e agosto fortes dependência espacial ao tempo em que, para as séries relativas a janeiro, março, setembro, outubro e novembro apresentaram moderada dependência espacial e para as séries relativas aos meses de abril, maio, junho, julho e dezembro independência espacial dos dados. 


\section{Referências}

ASSUNÇÃO, W. L. Climatologia da cafeicultura irrigada no município de Araguari (MG). 2002. 282 f. Tese (doutorado em Geografia) - Faculdade de Ciências e Tecnologia da Universidade Estadual Paulista: Campus de Presidente Prudente. Presidente Prudente (SP). 2002.

AYOADE, J. O. Introdução à climatologia para os trópicos; tradução de Maria Juraci Zani

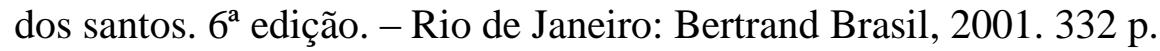

NIMER, E. Climatologia do Brasil. Rio de Janeiro: IBGE, 1979. 422p.

THORTNTHWAITE, H. L. An approach toward a rational classification of climate, Geographical Review, London, 38: 55-94, 1948.

BAILEY, R. Irrigated crops and their management. London: Farming Press Book, 1990. BRATH, A.; MONTANARI, A.; TOTH, E. Analysis of the effects of different scenarios of historical data availability on the calibration of a spatially-distributed hydrological model. Journal of Hidrology, Burlington, n. 291, p. 232-253, 2004.

GUERRA, P. A. G. Geoestatística operacional. Brasília: Ministério de Minas e Energia/DNPM, 1988.

ISAAKS, E. H.; SRIVASTAVA, R. M. Applied geostatistics. New York: Oxford University Press, 1989.

LANDIM, P. M. B.; STURARO, J. R. Krigagem Indicativa aplicada à elaboração de mapas probabilísticos de riscos. Rio Claro: IGCE/UNESP, 2002. Texto Didático. Disponível em: $K$ http://www.rc.unesp.br/igce/aplicada/textodi.html > Acesso em: 16 abr. 2009.

LANNA, A. E. Elementos de Estatística e Probabilidades. In: TUCCI, C. E. M. Hidrologia: ciência e aplicação. Porto Alegre: Editora da Universidade Federal do Rio Grande do Sul, 1997. p.79- 176.

PHILLIPS, D. L.; DOLPH, J.; MARKS, D. A comparison of geostatistical procedures for spatial analysis of precipitation in montainous terrain. Agricultural and Forest Meteorology, Amsterdam, v. 58, p. 119-141, 1992.

RIBEIRO, A. M. de A.; LUNARDI, D. M. C. A Precipitação Mensal Provável para Londrina - PR, através da Função Gama. Energia na Agricultura, Botucatu, v. 12, n. 4, p. 37-44, out/dez. 1997.

SOARES, A. Geoestatística para as ciências da terra e do ambiente. Lisboa: IST Press, 2000 . 